synovitis, a total number of US wrist synovitis was detected at $30(15 \%)$ radioulnar (of which half was Doppler +), $91(45.5 \%)$ radiocarpal (of which 60\% was Doppler +) and 105 (52.5\%) intercarpal joints (of which 67\% was Doppler +). Concerning the MCP and PIP joints, the most frequent location of subclinical synovitis were 1 st MCP in 51 cases $(25.5 \%)$, 4th MCP in 49 cases $(24.5 \%)$, 5th MCP in 50 of cases $(25 \%), 1$ st PIP in 24 cases (12\%) and 5 th PIP in 22 cases (11\%).

Conclusions: Our study highlighted the low sensitivity of physical examination of synovitis in hand and wrist joints, especially in some locations. We showed the most frequent location for detecting subclinical synovitis were radiocarpal and intercarpal joint, 1st-4th -5th MCP and 1st-5th PIP. About half of those subclinical synovitis were Doppler +.

Disclosure of Interest: None declared

DOI: 10.1136/annrheumdis-2018-eular.5546

\section{SAT0163 ABSOLUTE NUMBER OF PERIPHERAL CD4-CD25 +FOXP3+T CELLS DECREASES AND RESTORES AFTER LOW-DOSE INTERLEUKIN-2 TREATMENT IN RHEUMATOID ARTHRITIS}

X. Jia ${ }^{1}$, H. An ${ }^{1}$, K. Fan ${ }^{1}$, F. Li ${ }^{1}$, C. Gao ${ }^{2}$, X. Li ${ }^{1} .{ }^{1}$ Rheumatology, The Second Hospital Of Shanxi Medical University, Taiyuan, China, ${ }^{2}$ Pathology, Brigham and Women's Hospital, Boston, United States

Background: Recently, several studies have suggested that abnormal quantity and function of regulatory $T$ cells (Tregs) may play a vital role in the development of rheumatoid arthritis (RA). CD25+FOXP3 ${ }^{+}$T cells include $\mathrm{CD}^{+}\left(\mathrm{CD} 4^{+}\right.$Tregs) and $\mathrm{CD}^{+}$cells $\left(\mathrm{CD} 8^{+}\right.$Tregs). Recently studies have shown that $\mathrm{CD} 8^{+}$Tregs also have immunosuppressive function, similar to even stronger than $\mathrm{CD} 4^{+}$Tregs, and are more sensitive to IL-2 in vivo. However, the status of CD8+Treg cells in RA is unknown.

Objectives: Our study was designed to clarify the level of CD4 $4^{-} \mathrm{CD} 25^{+} \mathrm{FOXP} 3^{+} \mathrm{T}$ cells in RA patients, and to investigate the role of low-dose interleukin-2 (IL-2) therapy in the regulation of $\mathrm{CD} 4^{-} \mathrm{CD} 25^{+} \mathrm{FOXP} 3^{+} \mathrm{T}$ cells in RA patients to provide another theoretical basis besides CD4 ${ }^{+}$Tregs to IL-2 therapy.

Methods: Three hundred and four RA patients (diagnosis according to the 2010 ACR criteria) were enrolled; no treatment group $(\mathrm{N}=75)$, DMARDs treatment group $(\mathrm{N}=73$ ), low dose IL-2 treatment group (50WIU/day $\times 5$ days, subcutaneous injection) $(N=156)$, and healthy control group $(N=90)$. The absolute numbers of $\mathrm{CD}^{-} \mathrm{CD} 25^{+} \mathrm{FOXP3}{ }^{+} \mathrm{T}$ cells in peripheral blood were detected by flow cytometry. We assumed that $\mathrm{CD} 4^{-} \mathrm{T}$ cells with $\mathrm{CD} 25^{+}$and $\mathrm{FOXP3}^{+}$were mostly $\mathrm{CD}^{+}{ }^{+} \mathrm{CD} 25^{+} \mathrm{FOXP}^{+}$Treg cells, which was $\mathrm{CD}^{-} \mathrm{CD}^{-} 5^{+} \mathrm{FOXP}^{+} \mathrm{T}$ cells in this study. The levels of $\mathrm{CD} 4^{-} \mathrm{CD} 25^{+} \mathrm{FOXP} 3^{+} \mathrm{T}$ cells among these groups were compared with that of health group or each other respectively, and then the statistical software SPSS 20.0 was used for analysis; $p<0.05$ was considered significant. Results: As compared with the healthy group, the absolute number of $\mathrm{CD}^{-} \mathrm{CD}^{2} 5^{+} \mathrm{FOXP}^{+} \mathrm{T}$ cells decreased significantly in the untreated RA patients $[0.94(0.41,1.61)$ vs $1.31(0.72,2.52), P<0.001]$ and more dramatically in DMARDs treatment patients $[0.86(0.36,1.83)$ vs $1.31(0.72,2.52), \mathrm{P}<0.01]$. After treatment with IL-2, the absolute count of $\mathrm{CD} 4^{-} \mathrm{CD} 25^{+} \mathrm{FOXP} 3^{+} \mathrm{T}$ cells increased significantly compared with that before treatment $[0.91(0.48,1.54)$ vs $2.10(1.12,3.56)$, $\mathrm{P}<0.001]$.
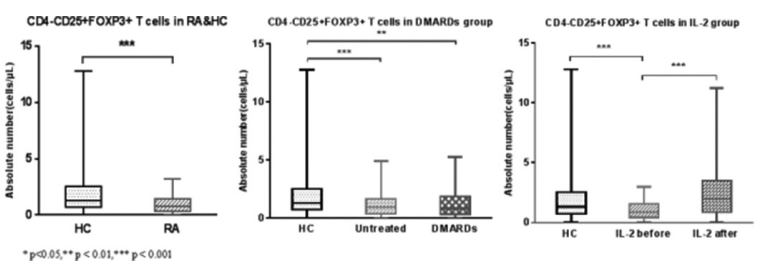

Conclusions: The absolute number of $\mathrm{CD} 4^{-} \mathrm{CD} 25^{+} \mathrm{FOXP} 3^{+} \mathrm{T}$ cells in untreated RA patients were lower than those health, implying that $C D 4 C D 25^{+} \mathrm{FOXP3}^{+} \mathrm{T}$ cells deficiency was caused by disease itself but not immunosuppressive therapy, which may be an important factor in the pathogenesis of RA. The traditional DMARDs therapy did not improve this reduction. Low dose IL-2 can increase the absolute number of $\mathrm{CD}^{-} \mathrm{CD} 25^{+} \mathrm{FOXP3}{ }^{+} \mathrm{T}$ cells in peripheral blood. We are about to detect the number of $\mathrm{CD}^{+} \mathrm{CD} 25^{+} \mathrm{FOXP} 3^{+}$Treg cells accurately to verify this theory.

Disclosure of Interest: None declared

DOI: 10.1136/annrheumdis-2018-eular.4123

\section{SAT0164 \\ ADVERSE DRUG REACTIONS DUE TO DISEASE MODIFYING DRUGS IN PATIENTS WITH INCIDENT RHEUMATOID ARTHRITIS}

Z. Rosales Rosado ${ }^{1,2}$, D. D. Freites NÚÑEZZ2, C. Lajas Petisco ${ }^{1}$, E. Pato Cour ${ }^{1}$, L. León Mateos ${ }^{2}$, L. Abásolo Alcázar ${ }^{2}{ }^{1}$ Rheumatology, hospital clínico san carlos,

${ }^{2}$ Instituto De Investigación Sanitaria San Carlos, Madrid, Spain

Background: There is a well-known risk of developing adverse drug reactions $(A D R)$ in rheumatology due, mainly, to the Disease Modifying Antirheumatic Drugs (DMARD) used. There is no doubt about their efficacy in Rheumatoid Arthritis (RA), but it is necessary to increase our knowledge of their ADR, especially those that lead to discontinuation

Objectives: To describe the incidence and characteristics of ADR related with DMARD in patients with incident RA as well as the factors involved in their development

Methods: Observational retrospective longitudinal study between April 15th 2007 and December 31st 2016. Inclusion criteria: patients diagnosed with RA between April 15th 2007 and June 31st 2011 followed until December 31st 2016 whom started any DMARD. Primary endpoint: development of an ADR that required discontinuation of the DMARD (moderate: discontinuation; severe: discontinuation with hospitalization or death). Co-variables: sociodemographic; clinical and therapy. Statistical analysis: incidence rates of discontinuation (IR) per 100 patient-years were estimated using survival techniques with their respective $95 \%$ confidence interval $[\mathrm{Cl}]$. Comparisons between associated factors were run by Cox bivariate and multivariate regression models. Results were expressed by hazard ratio $(\mathrm{HR})$ and $[\mathrm{Cl}]$

Results: We included 1054 courses of DMARD treatment in 405 patients (2277.9 patient-years). $78.3 \%$ were women with a mean age at diagnosis of 57 \pm 15 years. During follow-up, $16.3 \%$ of patients were taking biological DMARD, $73.3 \%$ were using monotherapy and $89 \%$ were taking corticoids. There were 369 ADR in 212 patients, $88.9 \%$ moderate. Gastrointestinal was the most frequent cause of ADR (26.3\%), followed by infections (12.2\%). IR are shown in table 1 and the multivariate analysis in table 2. Regarding type of DMARD, Abatacept had the highest risk of ADR development (HR:4.9[2.1-11.2]) compared to the other drugs followed by Gold (HR:1.6[1-2.6]) and Leflunomide (HR:1.4[1.1-1.9]). Methotrexate was the safest drug compared with the others $(0.6[0.5-0.8])$

\begin{tabular}{lllll} 
Table 1 & & & & \\
\hline Global & 2277.9 & 369 & 16.2 & $14.6-17.9$ \\
Women & 1835.4 & 296 & 16.1 & $14.4-18.1$ \\
Men & 442.5 & 73 & 16.5 & $13.1-20.7$ \\
\hline By therapy & 1609.5 & 200 & 12.4 & $10.8-14.3$ \\
regimen & 568.9 & 132 & 23.2 & $19.6-27.5$ \\
Monotherapy & 99.4 & 37 & 37.2 & $26.9-51.4$ \\
Double therapy & & & & \\
Triple therapy & & & & \\
By type of DMARD & 2048.3 & 326 & 15.9 & $14.3-17.7$ \\
Synthetic & 229.5 & 43 & 18.7 & $13.9-25.3$ \\
Biological & & & & \\
By drug & 8.3 & 5 & 60.6 & $25.2-$ \\
Abatacept & 81.5 & 10 & 12.3 & 145.5 \\
Adalimumab & 749.7 & 157 & 20.9 & $6.6-22.8$ \\
Antimalarials & 19 & 3 & 15.7 & $17.9-24.5$ \\
Azathioprine & 16 & 4 & 24.8 & $5.1-48.8$ \\
Certolizumab & 65.2 & 12 & 18.4 & $9.3-66.2$ \\
Etanercept & 9.1 & 5 & 54.9 & $10.5-32.4$ \\
Golimumab & 18.4 & 6 & 32.7 & $22.9-$ \\
Infliximab & 340.4 & 85 & 25 & 131.9 \\
Leflunomide & 1463.5 & 206 & 14.1 & $14.7-72.7$ \\
Methotrexate & 83.6 & 33 & 39.5 & $20.2-30.9$ \\
Gold & 26.3 & 1 & 3.8 & $12.3-16.1$ \\
Rituximab & 154 & 45 & 29.2 & $28-55.5$ \\
Sulfasalazine & & & & $0.5-27$ \\
& & & & $21.8-39.1$ \\
\hline & & &
\end{tabular}

Table 2

\begin{tabular}{llll}
\hline Monotherapy & 1 & - & - \\
Double therapy & 2 & $1.5-$ & 00 \\
Triple therapy & 4.2 & 2.5 & \\
& & $2.6-$ & \\
& & 6.8 & 0.002 \\
\hline Congestive heart & 1.8 & $1.2-$ & \\
failure & & 2.7 & 0.012 \\
Liver disease & 2 & $1.2-$ & \\
& & 3.3 & \\
\hline
\end{tabular}


Conclusions: The IR of ADRwas $16.2 \%$, being similar in all age categories Gastrointestinal was the main cause of ADR followed by infections. We have found differences in discontinuation rates among DMARD due to ADR, being Abatacept, Gold and Leflunomide the drugs with the highest risk. Methotrexate had a lower risk of ADR compared to other DMARD. Caution should be taken in patients receiving combined therapy and with certain comorbidities

Disclosure of Interest: None declared

DOI: 10.1136/annrheumdis-2018-eular.2473

Saturday, 16 JUNE 2018

Rheumatoid arthritis - biological DMARDs

\section{SAT0165 REASONS FOR BDMARD CESSATION AND SUBSEQUENT PERSISTENCE OF SECOND LINE TREATMENT IN A LARGE REAL WORLD RHEUMATOID ARTHRITIS REGISTRY}

P. Youssef ${ }^{1}$, B. Marcal $\left.\right|^{2}$, P. Button ${ }^{3}$, M. Truman ${ }^{3}$, P. Bird ${ }^{4}$, H. Griffiths ${ }^{5}$, L. Roberts ${ }^{6}$, K. Tymms ${ }^{7}$, G. Littlejohn ${ }^{8} .{ }^{1}$ Royal Prince Alfred Hospital, Camperdown, ${ }^{2}$ Roche Products, Pty. Limited, ${ }^{3} \mathrm{OzB}$ Biostat Pty. Ltd., ${ }^{4}$ University of New South Wales, Sydney, ${ }^{5}$ Barwon Rheumatology Service, Geelong, ${ }^{6}$ Monash Rheumatology, Clayton, ${ }^{7}$ Canberra Rheumatology, Canberra, ${ }^{8}$ Monash University, Clayton, Australia

Background: The current recommendations for treating Rheumatoid Arthritis (RA) patients (pts) who fail on conventional disease modifying anti-rheumatic drugs (DMARDs) is to use biologic (b) or targeted synthetic (ts) DMARDs. Pts who fail first (1st) line b/tsDMRADs are recommended to go on other b/tsDMARDs; however, reasons for stopping or switching between bDMARDs according to mode of action and the persistence on treatment are not well characterized in real world patient populations.

Objectives: The primary objective was to identify the reasons for stopping 1st line b/tsDMARDs in RA pts treated in the clinical practice setting. The secondary objectives were to identify second (2nd) line b/tsDMARDs choices in pts who stop TNF inhibitors (TNFis) within 6 months (mo) due to lack of efficacy and the persistence on these treatments.

Methods: Pts $\geq 18$ years with confirmed RA who were treated with 1 st line b/ tsDMARDs, from 1 August 2010 to 30 June 2017, by physicians participating in the OPAL-QUMI database, were included in the analyses. Reasons for stopping $\mathrm{b} / \mathrm{tsDMARD}$ s were recorded by the treating physician during routine visits. The following b/tsDMARDs were included abatacept (ABA), adalimumab, certolizumab pegol, etanercept, golimumab, infliximab and tocilizumab (TCZ), rituximab (RTX) and tofacitinib (TFB). Data were analysed using descriptive statistics for continuous variables and frequency counts for categorical variables. Persistence on treatment was summarised using Kaplan-Meier (K-M) methodology. Individual TNFis were combined for simplicity.

Abstract Sat0165 - Table 1. Patients receiving 1st line treatment by mechanism of action.

\begin{tabular}{|c|c|c|c|c|c|}
\hline First-line Treatment & RTX & TCZ & TFB & ABA & TNFis \\
\hline Started, $\mathbf{n}$ & 230 & 555 & 518 & 609 & 5002 \\
\hline Stopped, n(\%) & $51(22)$ & $238(43)$ & $105(20)$ & $233(38)$ & $2029(41)$ \\
\hline Stopped within 6 months; $\mathrm{n}(\%)^{z}$ & $11(22)^{*}$ & $41(17)^{s *}$ & $57(54)$ & $72(31)^{5}$ & $733(36)^{*}$ \\
\hline \multicolumn{6}{|c|}{ percentage relative to subset stopped treatment } \\
\hline \multicolumn{6}{|c|}{${ }^{*}<<0.001:$ RTX vs TFB; TCZ vs ABA; TNFis vs TFB } \\
\hline
\end{tabular}

Abstract Sat0165 - Table 2 K-M. estimates of persistence on 2nd line b/tsDMARDs after discontinuation of 1 st line TNFis due to lack of efficacy.

\begin{tabular}{|c|c|c|c|c|c|}
\hline & RTX & TCZ & TFB & $\mathrm{ABA}$ & TNFis \\
\hline $\mathrm{N}$ & 13 & 49 & 25 & 92 & 130 \\
\hline 6 months, $\%$ & 75 & 78 & 71 & 61 & 60 \\
\hline 12 months, $\%$ & 75 & 57 & ND & 49 & 40 \\
\hline
\end{tabular}

Results: A total of 6914 pts received 1st line b/tsDMARDs. Median age was 61 years, median disease duration (RA onset to last visit) was 10 years. The majority
(75\%) were females. Treatment was stopped in 2656 pts (38\%); 914 (34\%) of these stopped within 6 mo of treatment initiation. The highest and lowest percentage of pts stopping treatment within 6 mo was in pts receiving TFB (54\%) and TCZ (17\%), respectively (table 1). The most common reasons for stopping therapy within 6 mo were lack of efficacy (45\%>ABA, 44\%>TNFis, 33\%>TFB and $27 \%>$ TCZ) and adverse reactions (21\%>TFB, 20\%>TCZ, $15 \%>$ TNFis, $13 \%$ $>A B A)$. Stopping due to lack of efficacy-primary failure was highest for TFB $(23 \%)$. The percentage of pts remaining on 2 nd line b/tsDMARD treatment after stopping 1 st line TNFis due to lack of efficacy was the highest for TCZ (78\%) at 6 mo and RTX (75\%) at 12 mo (table 2). Median time to stopping 2 nd line treatment was $48 \mathrm{mo}(95 \% \mathrm{Cl}: 17-74)$ for RTX, $21 \mathrm{mo}$ (95\% Cl:11-62) for TCZ, $21 \mathrm{mo}$ (95\% $\mathrm{Cl}: 6-21)$ for TFB; $11 \mathrm{mo}$ (95\% Cl:8-22) for ABA and 9 mo (95\% Cl:7-12) TNFis. Conclusions: The primary failure rate is lower than previously reported. In pts who failed 1st line TNFis within 6 mo of commencement due to lack of efficacy 2nd line TNFis resulted in the lowest treatment persistence. These real world data will assist clinicians with treatment choices post primary TNFis failure.

Acknowledgements: Sponsored by Roche Products, Pty. Limited. Medica Writing provided by Dr Joseline Ojaimi from Roche.

Disclosure of Interest: P. Youssef: None declared, B. Marcal Employee of: Roche Products, Pty. Limited, P. Button Consultant for: Roche Products, Pty. Limited, M. Truman Consultant for: Roche Products, Pty. Limited, P. Bird: None declared, H. Griffiths: None declared, L. Roberts Consultant for: AbbVie, BristolMyers Squibb, Janssen, Pfizer, Roche Products, Pty. Limited, UCB, K. Tymms Consultant for: AbbVie, Bristol-Myers Squibb, Janssen, Pfizer, Roche Products, Pty. Limited, UCB, G. Littlejohn Consultant for: AbbVie, Bristol-Myers Squibb, Janssen, Pfizer, Roche Products, Pty. Limited, UCB

DOI: 10.1136/annrheumdis-2018-eular.6022

\section{SAT0166 WHICH BIOLOGIC AGENT IS MOST SUITABLE FOR AN EXTENDED-INTERVAL TREATMENT FOR RHEUMATOID ARTHRITIS ? RESULTS FROM A MULTICENTER STUDY}

K. Katayama ${ }^{1}$, H. Matsuno ${ }^{2}$, T. Matsubara ${ }^{3} .{ }^{1}$ Orthopedic Surgery, Katayama Orthopedic Rheumatology Clinic, Asahikawa, ${ }^{2}$ Orthopedic Surgery, Matsuno Clinic for Rheumatic Diseases, Toyama, ${ }^{3}$ Orthopedic Surgery, Matsubara Mayflower Hospital, Kobe, Japan

Background: Biological disease-modifying antirheumatic drugs (bDMARDs) have made apparent development of treating rheumatoid arthritis (RA). However, prescription of them appeared to be relatively difficult due to high cost. The newest EULAR recommendation advocates tapering of bDMARDs when RA activity is controlled.

Objectives: A multicenter clinical study on a longer interval treatment with three bDMARDs, Golimumab (GOL), which is one of TNF inhibitors, and two of nonTNF inhibitor, Tocilizumab (TCZ) and Abatacept (ABT) was investigated.

Methods: Patients, who were maintained at low disease activity by DAS28 score for more than 3 months treated with GLM, TCZ, ABT, were enrolled. These selected patients were treated with these drugs with 1.5 fold longer interval of standard schedule for 60 weeks, and the rate of patients, who preserved low dis ease activity were determined. The patients who were not tolerated these drugs because of the side effects or adverse events, were withdrawn from this study.

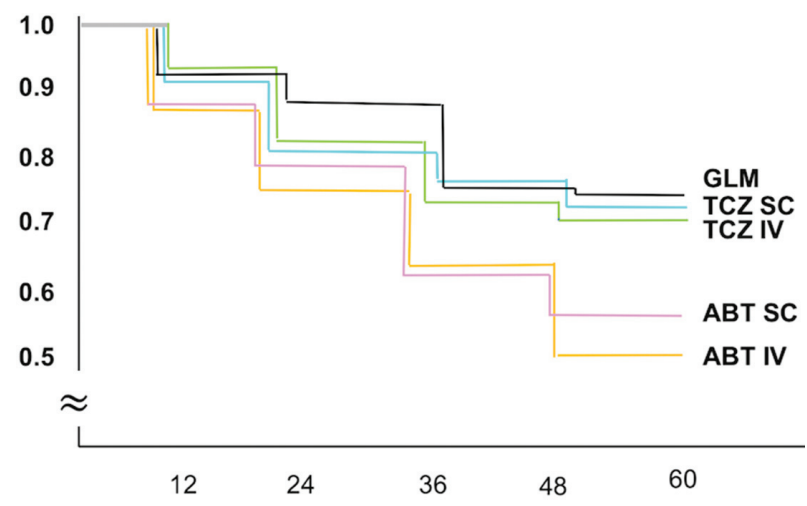

Results: One hundred thirty-one patients treated with GLM, 149 with ABT (S.C 61, I.V. 88) and 299 with TCZ (S.C. 87, I.V. 212) were enrolled. Among these, 57 patients treated with GLM (43\%), 40 with ABT(26\%, S.C 18, I.V 22), 93 with TCZ $(31 \%$, S.C 21, I.V 72$)$ were successfully maintained at low disease activity with 